\title{
GCU
}

Glasgow Caledonian

University

University for the Common Good

\section{Widening access to writing support: beliefs about the writing process are key}

Kempenaar, Larissa; Murray, Rowena

Published in:

Journal of Further and Higher Education

DOI:

10.1080/0309877X.2018.1450964

Publication date:

2019

Document Version

Author accepted manuscript

Link to publication in ResearchOnline

Citation for published version (Harvard):

Kempenaar, L \& Murray, R 2019, 'Widening access to writing support: beliefs about the writing process are key', Journal of Further and Higher Education, vol. 43, no. 8, pp. 1109-1119.

https://doi.org/10.1080/0309877X.2018.1450964

\section{General rights}

Copyright and moral rights for the publications made accessible in the public portal are retained by the authors and/or other copyright owners and it is a condition of accessing publications that users recognise and abide by the legal requirements associated with these rights.

Take down policy

If you believe that this document breaches copyright please view our takedown policy at https://edshare.gcu.ac.uk/id/eprint/5179 for details of how to contact us. 


\title{
Widening access to writing support:
}

\section{Beliefs about the writing process are key}

\author{
Authors \\ Dr Larissa Kempenaar \\ School of Health and Life Sciences, Glasgow Caledonian University, Cowcaddens Road, \\ Glasgow, G4 0BA, United Kingdom* \\ Email: 1.kempenaar@gcu.ac.uk (ORCID 0000-0002-6259-2035) \\ https://uk.linkedin.com/in/larissakempenaar
}

Professor Rowena Murray

School of Education, University of the West of Scotland, University Avenue, Ayr, KA8 0SX, United Kingdom

Email: rowena.murray@uws.ac.uk (ORCID 0000-0002-3209-9290)

*corresponding author

\section{Biographical notes}

Larissa Kempenaar graduated with a $\mathrm{PhD}$ from Glasgow Caledonian University. She was Associate Lecturer in the School of Education, at the University of the West of Scotland, where she worked with Professor Murray to coordinate, evaluate and research writing retreats. She is a Physiotherapy lecturer in the School of Health and Life Sciences at Glasgow Caledonian University. Her research interests include academic writing and writing processes.

Rowena Murray graduated with MA (Hons) from Glasgow University and $\mathrm{PhD}$ from the Pennsylvania State University. She is Professor of Education at the University of the West of Scotland and Principal Fellow of the UK Higher Education Academy. Her teaching and research focus on academic writing, the subject of her many articles and books. Her research has been funded by the British Academy, the Carnegie Trust and the Nuffield Foundation. 


\begin{abstract}
Universities' performance indicators for scholarly outputs depend on academics having productive and sustainable writing behaviours. Research shows that writing programmes can increase research output, but less is known about which writing processes are productive. A project was initiated at a university which widened access to writing support to include staff who were not included in these performance targets, but who might be in the future. Following a writing for publication workshop, 36 academics were offered a place at a structured writing retreat. The evaluation aimed to increase our understanding of participants' perceptions of their writing skills and processes before and after the retreat using a transactional model. We found that participants' perceptions of their writing abilities were greater than their perceptions of their ability to employ effective writing practices. Both scores improved after the retreat. This finding confirms that a structured writing retreat provides an environment and structure for academics to practise effective writing. It enhances self-belief in the processes and skills required to produce output. Widening access to writing support for academics is essential for success in performance-based systems. Writing support must provide opportunities for academics to develop strong performance beliefs by practising writing skills and productive and sustainable writing processes.
\end{abstract}

\title{
Key Words
}

Academic writing, writing behaviour, writing retreats, research output

\section{Acknowledgement}

This work was supported by the Research Services Department at the University of the West of Scotland.

\section{Word count 6,638}




\section{Introduction}

Performance based funding systems which determine Universities' performance indicators in terms of research and scholarly papers, as well as teaching and learning accreditation, are based on academic staff's ability to produce high quality research and scholarly publications (Jongbloed and Vossensteyn 2016). Like most other HEIs, the University of the West of Scotland has, therefore, included the number of research outputs as one of its institutional performance indicators. In order to produce this output and achieve the institutional targets, it is essential that staff have both writing skills (Lillis and Curry 2010) and productive and sustainable writing behaviours (Boice and Johnson 1984).

There are many examples of studies which demonstrate that writing programmes, such as writing retreats, are effective at increasing publication rates (e.g. Dickson-Swift et al. 2009; Herman, Abate and Walker 2013; Johnston et al. 2014; McGrail, Rickard and Jones 2006; Paliadelis, Parker and Parmenter 2015; Pololi, Knight and Dunn 2004). However, fewer papers focus on which specific writing processes are effective; nor do they focus on which processes are required to make writing support effective. In addition, not everyone has access to a writing programme, and it is difficult for writing programmes to integrate all the developmental functions and provide all the support that may be needed.

In an effort to support academic staff to produce research and scholarly output, the 'pipeline project' was initiated by the Research and Enterprise Department at the University of the West of Scotland (UWS). UWS is a 'widening access' university, and the 'pipeline' in this paper refers to the concept of widening access to writing support for staff who normally do not receive this kind of support. This is because they have not been viewed as key players in

performance based research funding frameworks. In light of the recent recommendations of a UK report (Stern 2016) to include all 'research-active' staff in the research excellence assessment, a 'widening access' approach appears increasingly important to improve scholarly activity.

To facilitate wider access, the pipeline project aimed to increase effective writing practices amongst academic staff using a structured writing retreat (SWR) model. SWRs have been running monthly at UWS since 2013 and have been shown to be effective as a means of developing communities of practice of writers, including new and experienced writers (Murray and Newton 2009, Knowles 2017), and producing research output (Kornhaber et al 2016). SWRs are 2.5-day residential writing retreats with fixed time slots for goal setting, 
peer support and writing (Murray and Newton 2009). All participants write in the same room, based on a typing pool model of writing (Murray and Newton 2009). The venue is isolated, with poor access to the internet, and participants share meals, physical activity and social times. In addition, SWRs provide a nurturing environment, through reciprocal support and in terms of good food and comfortable accommodation. All these components create a safe environment in which task primacy of writing is unambiguous, and a community of practice is fostered.

One of the core principles of SWRs is the facilitation of effective and sustainable writing behaviours by providing a structure, in terms of a programme of fixed writing slots. MacLeod, Steckley and Murray (2012) reported that task primacy is frequently ambiguous for academics when there are competing demands for limited time in terms of increasing teaching loads and performance targets for administration and research output. This issue is addressed in SWRs by means of clear leadership. Leadership at these retreats acts to maintain the boundaries around writing time and ensures writing is the sole priority of participants. SWRs therefore enable participants to experience writing behaviours which are sustainable and productive by removing the ambiguity around task primacy.

There is no tuition or instruction included in the retreat programme, as one of the underpinning assumptions of the organisers is that most academics have sufficient skills to structure and compose writing (Moore 2003). However, because these participants had not published regularly, we offered a writing for publication workshop, which included discussion on how to prepare for the retreat.

Likewise, feedback on individuals' writing is not structured into the retreat, as this is assumed to be provided by the academics' peers and supervisors in their departments. In contrast, it is assumed that staff who have not attended retreats before are likely to be less practised and hence less confident and more challenged in the writing processes required to carry out writing behaviour. In other words, we assumed that academic staff had sufficient belief in knowing what to write and how to write, but less self-belief and felt less supported in their ability to organise time and space to prioritise writing.

In order to look at academics' beliefs more closely, we chose a transactional approach for our analysis. As we have explained more fully elsewhere (Kempenaar and Murray 2016), the transactional approach is one way of identifying how academics' beliefs affect their writing productivity. The transactional approach considers writing a behaviour. While it deems the 
system in which the individual is positioned to be equally important, we focused on the transactional approach so as to explore participants' beliefs. This approach assumes that beliefs about the relationship between a range of domains (person, performance, process, outcome and profit) need to be of sufficient strength for writing to take place (Kempenaar and Murray 2016). Beliefs about both writing skills and writing processes can be viewed as performance beliefs within a transactional approach. Performance beliefs are those beliefs that the individual holds about their abilities to perform a behaviour (Van Egeren 2000). While research has identified characteristics of prolific writers (e.g. Boice and Johnson 1984), which beliefs are core to writing is not known. Based on this assumption we propose that staff are less likely to write when, on the one hand, writing skills beliefs are sufficient to perform writing, but, on the other hand, the strength of belief in writing process is insufficient. Having self-belief in both writing skills and writing processes is therefore considered essential to the performance of writing behaviour.

In this paper we present the findings of an evaluation of writing skills and writing process beliefs in a group of academic staff who had been identified as requiring support to publish and who had not attended a writing retreat before.

\section{Methods}

\section{Recruitment}

Fifty places at five SWRs were booked and paid for by the university's Research Services Department. No funding was allocated for release of staff time to attend the writing workshop and retreat. Associate Deans of Research across the university's six Schools were invited by the Head of Research Services to nominate a total of 50 members of staff, which meant that there was an element of targeting but also of self-selection. Staff nominated were early career staff or staff who needed support to write for publication and would benefit from attending the writing retreat. All participants were offered attendance at a structured writing retreat, once they had attended a Writing for Publication workshops. This allowed participants time to prepare their writing projects before attending the SWR, which consisted solely of writing time. Participants were given two dates for the workshop and several dates for the SWR to facilitate fitting these in with their workload and teaching commitments. 
It was explained at the start of the workshop that its purpose was explicitly to introduce a range of writing strategies that could be used at a writing retreat. It was made explicit that the purpose of the workshop was to support participants, because most of them had never attended a retreat before. It was explained that because the SWR initiates a significant change in writing behaviours, this combination of workshop and retreat was recommended to help them engage with the retreat approach and raise any questions they might have.

Our main observation about the workshop is that it was very positively received by most, although some seemed a bit circumspect, which might have related to the institutional targets for publications. The provision of institutional funding in this context could therefore be see as a double-edged sword: some valued the institutional support; others resisted the institutional driver. We discussed these matters in the workshop, with a view to helping participants develop their own motivation for writing and their beliefs that they could use the approaches provided in the workshop to write at the retreat.

\section{Intervention}

The writing workshop consisted of a half-day training course, including topics such as approaches to writing, writing to prompts, using verbs to develop focus and define purpose, abstract construction, preparing to write, dealing with editors' and reviewers' feedback, goal setting, and preparing for a structured writing retreat. The workshop was delivered using presentations, writing analysis and activities, peer and group discussions, and peer review. A series of writing activities were used to develop ideas and draft titles and abstracts for the articles they would be writing at the SWR.

The SWR was a 2.5-day residential retreat in a rural location, approximately 45 minutes from Glasgow. During the retreat, based on the typing pool model, all participants wrote in a function room during day, with breaks for snacks and meals. Included in the structure were times for freewriting, goal-setting, monitoring and peer discussion. Based on a well-being model (Thow, Graham and Lee 2013; Tremblay et al 2010), participants wrote in fixed writing slots of 60 or 90 minutes, and time was included in the programme for physical activity or exercise before lunch and dinner. During the evening, participants were free to do as they pleased. 
Ten places were reserved for pipeline participants at each of five SWRs between January and June 2016. Four of the retreats took place from Wednesday until Friday; one retreat took place from Friday to Sunday.

\section{Evaluation}

Participants were asked to complete two short quizzes before and after each retreat: The Writing Skills Quiz and The Writing Process Quiz. These were developed by Academic Coaching and Writing LLC (C) and reproduced with their permission. The Writing Skills Quiz (Appendix 1) asks participants about their beliefs to perform a range of skills required for academic writing, including composition and structuring of a piece of writing. It consists of 10 questions to be rated by the participant, from 1 (poor ability) to 10 (excellent ability). By contrast, the Writing Process Quiz (Appendix 2) asks participants to rate their beliefs to perform a list of writing behaviours which are considered helpful with regard to productive writing. It also consists of 10 questions to be rated by the participant, from 1 (poor ability) to 10 (excellent ability). The quizzes were completed anonymously. While both have good face validity, content validity and reliability have not been established. However, while there are other available tools, the authors decided to use these quizzes because they were short and easy to use, thus less of an imposition on participants' time at the start and end of what was their first writing retreat, and because, in combination, they produced information to be used in identifying participants' beliefs. Quiz data were complete for 18 participants (incomplete data $n=5)$.

In addition to the quizzes, output data were gathered from participants at the end of the retreat in terms of word counts (recorded as the number of newly produced or edited words). Furthermore, quantitative data was complemented by qualitative data in terms of reviewing the experience of the retreat at the end of each retreat. During this review, all participants come together with tea and cake to celebrate and discuss the achievements of each participant.

Although all participants are asked to read out the word count produced or edited, participants volunteer to share their experiences of the retreat. 


\section{Analysis}

The differences between before and after scores for the Writing Skills and Writing Process Quizzes were calculated, and means and standard deviations were calculated for each quiz. Due to the small number of participants, no further statistical calculations were carried out. Written outputs were combined to provide total word counts of 'edited' and 'newly written' words for the various writing projects participants were working on. Comments made at the end of retreat review were analysed for common themes across the 5 retreats. While counting words may seem simplistic, it provides a concrete measure of performance and, more importantly, involves participants in monitoring the extent to which they achieved their writing goals, which is an important component of the development of self-efficacy in relation to writing. In addition, in practice, when participants talk about the number of words they have written at a writing retreat, they generally follow this up with an acknowledgement that this is just a first draft, and that they will have to work on it further, but that they have clarified the argument of their papers in the course of doing this writing. Moreover, for the participants in the pipeline project, who had struggled to produce such first drafts, these outcomes could be even more important. For these reasons, these concepts had been introduced to and discussed with participants at the Writing for Publication workshop and were explained, with this rationale provided, at the start of the writing retreat.

\section{Findings and Discussion}

\section{Who came to the structured writing retreats?}

Fifty members of staff were referred to the project by their Line Manager or Assistant Dean for Research. While 46 participants signed up for the workshops, 36 members of staff $(72 \%)$ attended one of the two workshops and were subsequently eligible to attend a structured writing retreat (see Figure 1). Four members of staff (8\%) chose not to engage with the project at all.

Participants were very positive about the workshop prior to the retreats and believed them to be the 'missing link' to writing for publication. Some staff suggested the Writing for Publication workshop should be made available to all new members of staff at the university. 
Of these 36 members of staff who attended a workshop, 27 (75\%) attended one or more retreats taking up 31 of the 50 pre-booked places $(61 \%)$. Three participants attended more than one retreat, as space had not been taken up by other members of staff. This suggests that while participants were nominated for this project, those who attended were self-selected to attend and were committed to adherence to the model.

We did not follow up with the small number of those who attended the workshop but not the retreat to find out why they did not attend because we judged that this was the responsibility of Assistant Deans and Line Managers, if they chose to do so. Several dates for retreats had been offered, in an attempt to mitigate timing clashes, but it might still have been impossible for them to be released from teaching duties. We have not included more information about participants in order to preserve their anonymity in such a small group.

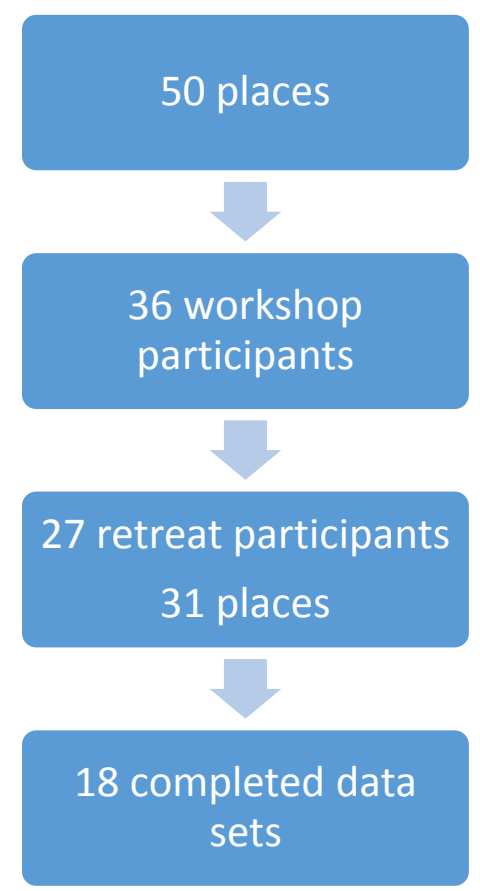

\section{Figure 1: Flowchart of attendance of participants}

Of the 27 participants, 20 (74\%) were female and 7 (25\%) were male. The evaluation data was obtained for 21 of these 27 participants (78\%). All participants were in full time, 
permanent employment with the University. Seven participants (33\%) had doctoral degrees. Of the remaining 14 staff, $11(52 \%)$ were working towards doctoral degrees.

\section{What did they write?}

Table 1 demonstrates the productivity of the participants during the 2.5-day retreat. A total of 234,729 words were written and edited. On average, each participant wrote 3,891 new words per retreat and edited 3,680 words per retreat, or 350 words per hour.

\begin{tabular}{|l|l|l|}
\hline Project & Type of work & $\begin{array}{l}\text { Number of } \\
\text { words }\end{array}$ \\
\hline $\begin{array}{l}\text { Doctoral } \\
\text { studies }\end{array}$ & New words written & 62,068 \\
\hline Journal article & New words written & \\
\hline & $\begin{array}{l}\text { Previously written (but not } \\
\text { yet submitted) work edited }\end{array}$ & 18,960 \\
\hline Conference & New words written & 26,660 \\
\hline Book chapter & New words written & 20,952 \\
\hline & Previously written work edited & 5,000 \\
\hline Grant & New words written & 750 \\
\hline HEA fellowship & New words written & 1,500 \\
\hline & Previously written work edited & 1,500 \\
\hline & Total words written & 234,729 \\
\hline & New words & 120,630 \\
\hline & Edited words & 114,099 \\
\hline
\end{tabular}

Table 1: Written output

Participants worked towards a number of writing projects. Although some participants wrote on one project, many worked on two or more projects during the retreat. Writing projects included book and thesis chapters, journal articles and applications for UK Higher Education Academy fellowships. 
From the output it can be seen that although the target audience for this project was early career staff and those who had not published for some time, nearly half of the participants were staff members who were undertaking doctoral degrees. While this may not have been the performance indicator that was the aim of this project, it meets another of university's performance indicators, increasing the number of academic staff in the university with doctoral qualifications. This suggests that while this project was aimed at early career lecturers or those who needed support to write, the need for writing support is an issue across a wide range of staff and is likely to apply to any staff who are undertaking a doctoral programme, require to publish research or scholarly papers, and those applying for grants, or accreditations with, for example, the Higher Education Academy. In the next section, we discuss findings in terms of participants' beliefs regarding their writing skills and processes.

\section{Perceived ability in writing skills and processes: I know how to construct my writing, but ...}

For the Writing Skills Quiz the average score before the retreat was 66.6 (SD 12.3, range 4498). On the one hand, this score of participants' perceived writing skills suggests that they were confident in their ability to compose academic writing before they came to the retreat. On the other hand, as these were staff nominated by their managers to increase their research output, this also suggests that having self-belief in their ability to compose academic writing is not sufficient to move an individual into action, i.e. to produce writing. This suggests that individuals had insufficient beliefs in other domains essential to productive writing practices.

This finding also suggests that offering skills-based writing programmes may not be sufficient to move individuals into action. Furthermore, it suggests that for any writing support to be effective it is essential to ensure all relevant performance beliefs are of sufficient strength for action to take place.

The average score in the Writing Process Quiz before the retreat was 51.9 (SD 13.8, range 18-80), considerably lower than the mean Writing Skills Quiz, suggesting that staff were more confident in their writing skills than in their ability to perform effective writing behaviours. The scores in the Writing Process Quiz support the previous assertion that to move individuals into action (i.e. writing), more than one domain of behaviour needs to be considered in order for us to support those who are not producing written output. 
After the retreat the Writing Skills Quiz score was 72.1 (SD 10.7, range 55-100), an increase of 5.3 points, indicating an improvement in the performance belief in the skills required for writing. The biggest change in a participant's score was an improvement of 21 points. This improvement is interesting, as the curriculum of the SWR does not include any teaching on writing, nor was feedback provided on any of the participants' writing. On the other hand, this suggests that the mere act of prioritizing and practising writing can increase participants' perceived skill levels through positive reinforcement (Bandura, 1997). This may also be facilitated by the structured goal setting and review discussions with peers that take place throughout the retreat to reflect on and celebrate progress.

The average score following the retreat in the Writing Process Quiz was 58.3 (SD 13.9, range 34-91). This was an increase of 6.4. The biggest change in a participant was an increase of 36 points. The improvement in the Writing Process Quiz indicates that staff became more confident in their ability to practice productive writing behaviours. This demonstrates that within the space of 2.5 days at a SWR, their perceptions of their ability in writing process can be improved. The transactional approach proposes that 'sufficient' strength of belief across relevant domains is required before an individual moves into action. This suggests a threshold or tipping point; however, it is not clear when this tipping point is achieved. All participants produced output at the retreat, suggesting that performance beliefs were sufficiently strong to move into action. Then again, it should be considered that performance beliefs, i.e. cognitive appraisals, are situation-specific (Lazarus and Folkman 1984), which suggests that while performance beliefs were adequate in the context of the retreat, they may be insufficient to transfer writing practices to the work-setting. This is reminiscent of other behavioural models such as the Stages of Change model which considers the 'tipping point' for changing health behaviours (Prochaska 2013). Another conceptualization of change which could be considered in this context is the 'threshold concept' (Meyer and Land 2003). The threshold concept proposes that there are 'conceptual gateways' or 'portals', which represent a new way of viewing something within a discipline. This could also be applied to threshold of beliefs in relation to a behaviour such as writing. More research is needed to explore how these concepts may help us to understand the question of 'how much?'.

The nature of retreats is such that the focus is solely on 'doing' the writing rather than providing instruction on writing behaviours. The structure, geographical isolation, lack of internet access, peer support, accommodation, catering and setting all contribute to create an environment where writing is prioritised. This again brings us back to writing being a 
behaviour. Any behaviour we aim to develop requires us to practise and reflect on our practice, as is common in theories of learning cycles (e.g. Kolb 2014).

This is also indicated in the comments received from staff during the end of retreat review, when the group collaboratively reflect on their experiences of the retreat. Some staff suggested that they wished to attend future retreats, now having a greater appreciation of how to prepare to write. This is also supported in the Writing Skills and Writing Process Quiz scores. While the Writing Process scores on average increased, they were still lower than the average score in the Writing Skills Quiz before the retreat. This suggests that while perceptions of the ability to perform effective writing behaviours has increased, the development of effective writing practices is a process of ongoing learning.

In this end-of-retreat discussion participants also reported that they found the structure of the writing retreats and the focussed time for writing, away from other responsibilities and daily distraction, very productive. Attendance at the writing retreat made them aware of how much progress could be made in a limited period of time. Participants also found the social interaction and ability to talk about research and sharing of ideas with academics from other disciplines, Schools and universities to be very encouraging and supportive.

More specifically, the first point raised in the first discussion at the end of the first retreat for 'pipeline' participants, was about whether there would be further support for their writing:

'What is the strategy for us? Will there be a follow up, or is it just the workshop plus the retreat?'

'This seems like it's a "one-shot" deal at the moment, but it would be useful to come back to retreat now that I understand how it works'.

Their writing beliefs therefore included the institution's role: was it to be 'follow up' or “"one-shot" deal'?

However, the main theme in pipeline participants' reflections was that there were changes they could already see in their writing practices, with many of their comments revealing changes in beliefs:

'Structuring my writing - I've never done that before, but I think the more you do it the easier it will be to judge what you can do in the time'. 
'Since the writing workshop I realise that the preparation is separate from the writing task. That's what I've learned. I've got through much more than I thought I would'.

'The idea of leaving a note for yourself at the end of each writing session was very good, especially for when you don't get back to your writing for a week or more, and you can't see what to do next'.

Many participants attributed these changes to what many retreat participants refer to as 'discipline', which is constructed by the fixed programme of writing time slots:

'It's the concentration - having a space away from home - it does a lot psychologically. It's hard to explain it'.

'I struggled at the end of each day to keep going, but it was very beneficial to do so.

Another important dimension of change in beliefs was that there could be a positive impact of writing with other people, talking to others about writing and taking motivation from writing in a group:

'I had no idea that working in a group would be so helpful'.

'Talking to other people with the same or different approaches was useful and led to some of the changes I made today'.

'Loved meeting like-minded people, bouncing ideas off each other. Emotional support as important as the word count'.

'One of biggest benefits of this retreat is not just to focus when you reach a low point but the ability to talk to other people and have support from them - I can't overstate the importance of that'.

These findings mirror the findings of many previous studies which have explored the development of communities of practice during the writing retreats (e.g. Dwyer et al 2015, Murray and Newton 2009).

\section{Conclusion}

The findings of this evaluation suggest that attendance at Structured Writing Retreats can enhance staff's perceptions of their writing skills. While the retreats did not include instruction in writing skills, they facilitated the construction of writing practices and beliefs. 
This suggests that performing the behaviour, i.e. constructing writing rather than receiving instruction only, is a useful way of improving staff's beliefs in their writing skills. However, participants' responses before the start of the retreats showed that their positive perceptions of their own writing skills were insufficient for them to produce research output. This may be linked to the institutional perception of them as not being key players in the institution's research league tables, but their responses focused on their self-beliefs, which is the focus for this paper and where our key finding lies. The writing retreat provided the structure, time and place to practice effective writing processes while constructing their writing. This form of retreat used for this project consisted of a programme of fixed writing slots, goal setting, peer discussion and clear leadership to maintain this structure (MacLeod, Steckley and Murray 2012). In addition, the development of a community of practice provided by the retreat participants enhanced participants' performance beliefs (Murray and Newton 2009) through sharing of space, time and experiences, thus facilitating reinforcement both internally and vicariously (Bandura 1997) that participants were able to engage with writing skills and processes to produce research output.

While improvements were noted during this project, there is room for further improvement in performance beliefs in both writing skills and process. This suggests that subsequent attendance at writing retreats is needed to provide continued opportunities to sustain these skills and processes. This was supported by staff's reflections that they were more aware of how to prepare for writing retreats and make best use of time at subsequent retreats. This is confirmed by feedback from other staff who attend retreats regularly, who report the benefit of 'serial-attendance' (Murray 2015). Research is needed, however, to establish if, and how, writing skills and processes might continue to develop over time, if participants were able to attend writing retreats on a regular basis. Conversely, more research is needed to establish if improvements in writing skills and processes, which were obtained in a short space of time in this project, are maintained over time for staff who attended only one retreat.

Within the scope of this project it was not possible to collate information on the number of submitted publications. It would be worthwhile to follow up participants after 12 months to establish how their publications have progressed. We would routinely do this with other participants, but measuring outputs was not the purpose of this study; instead, we focused mainly on identifying components of a transactional model that could add to our understanding of how writing may be facilitated or inhibited. The 'pipeline' project focused on getting people who were not currently writing to start writing, and this study was about 
learning more about this earlier phase in becoming an academic who writes. And the fact that over 200,000 words were produced evidences that this approach can increase productivity.

The Writing Skills and Writing Process quizzes were used because they were appropriate for this study's scope and in order to accommodate the participants. While they have face validity, they were originally developed as a learning tool rather than for evaluation. Future studies should focus on developing appropriate tools to capture specific writing processes that are relevant to sustainable and productive writing practices.

While the validity of word counts as an output can be debated, as performance-based funding systems are generally based on the quality or impact of peer reviewed publications, it is a useful marker of writing productivity during the retreats. Considering the 10.5 hours of writing during the retreat, participants were very productive as they produced on average nearly 4,000 new words per person, per retreat. The comment most often heard in criticism of word counts is that they are not representative of the quality of work. Our observation is that the writing of first drafts is what many participants struggle with. The production of a first draft means there is material for feedback, and many participants comment on the enhanced quality of their writing during the retreats. While we did not compare the quality of work produced at retreats, participants' reports suggest that the fixed time slots are not detrimental to the quality of work, but may indeed be beneficial.

By focussing on writing practices, this paper did not explicitly include the systems model within the transactional and systems approach (Kempenaar and Murray 2016). However, while it is important to ensure performance beliefs are sufficiently strong to engage with sustainable and productive writing practices, 'widening access' in this project refers to supportive exosystems (Bronfenbrenner 1977). Exosystems refer to the institutions individuals are based in. This study has demonstrated that widening access to writing support by means of a structured writing retreat can lead to considerable output as well as improving participants' performance beliefs about writing skills and productive and sustainable writing processes.

Access to writing support for academics will be essential for success in current performancebased funding systems. However, this resource should be accessible to all those who require to publish, not just the top research-active staff who are seen as key to achieving performance targets. Widening access should include consideration of staff's performance beliefs regarding writing skills, but also writing processes. Writing support should focus on 
providing opportunities for staff to grow strong performance beliefs in these domains by putting writing skills and productive and sustainable writing processes into practice.

\section{References}

Bandura, A. 1997. Self-efficacy: The exercise of control. New York: Freeman.

Boice, R., and K. Johnson. 1984. "Perception and practice of writing for publication by faculty at a doctoral-granting university." Research in Higher Education 21, 33-43. doi: 10.1007/BF00975034.

Dickson-Swift, V., E.L. James, S. Kippen, L. Talbot, G. Verrinder, and B. Ward. 2009. “A non-residential alternative to off campus writers' retreats for academics." Journal of Further and Higher Education 33(3): 229-239 http://dx.doi.org/10.1080/07294360.2016.1139553.

Dwyer, T., D. Friel, M. McAllister, K.R. Searl, and D. Rossi. 2015. “The write stuff: A proactive approach to increasing academics' writing skills and outcomes." Nurse Education in Practice 15(4): 321-326.

Herman, J., M. Abate, and T.E. Walker. 2013. "Faculty writing retreat: Fostering writing productivity, collaboration, and community-building through an interdisciplinary, multiday program." International Journal of University Teaching and Faculty Development 4(4): 193.

Johnston, J., S. Wilson., E. Rix, and S.W. Pit. 2014. "Publish or perish: strategies to help rural early career researchers increase publication output." Rural and Remote Health 14: 2870

Jongbloed, B., and H. Vossensteyn. 2016. "University funding and student funding: International comparisons." Oxford Review of Economic Policy 32(4): 576-595.

Kempenaar, L.E., and R. Murray. 2016. "Writing by academics: A transactional and systems approach to academic writing behaviours." Higher Education Research and Development 35(5): 940-950. 
Knowles, S.S. 2017. "Communities practising generous scholarship: Cultures of collegiality in academic writing retreats." In Implementing Communities of Practice in Higher Education, Edited by J. MacDonald, J. and A. Cater-Steel (53-80). Singapore: Springer.

Kolb, D.A. 2014. Experiential learning: Experience as the source of learning and development. Saddle River, NJ: Pearson Education.

Kornhaber, R., M. Cross, V. Betihavas, and H. Bridgman. 2016. "The benefits and challenges of academic writing retreats: An integrative review." Higher Education Research and Development 35(6): 1210-1227 http://dx.doi.org/10.1080/07294360.2016.1144572.

Lazarus, R.S., and S. Folkman. 1984. Stress, coping and appraisal. New York: Springer.

Lillis, T., and M.J. Curry. 2010. Academic writing in a global context: The politics and practices of publishing in English. London: Routledge.

McGrail, M.R., C.M. Rickard, and R. Jones. 2006. "Publish or perish: A systematic review of interventions to increase academic publication rates." Higher Education Research and Development 25(1):19-35.

MacLeod, I., L. Steckley, and R. Murray. 2012. "Time is not enough: Promoting strategic engagement with writing for publication." Studies in Higher Education 37(6): 641-654.

Meyer, J., and R. Land. 2003. Threshold concepts and troublesome knowledge: Linkages to ways of thinking and practising within the disciplines. Edinburgh: University of Edinburgh.

Moore, S. 2003. "Writers' retreats for academics: Exploring and increasing the motivation to write." Journal of Further and Higher Education 27: 333-342 doi:10.1080/0309877032000098734.

Murray, R., and M. Newton. 2009. "Writing retreat as structured intervention: margin or mainstream?" Higher Education Research and Development 28(5): 541-553.

Murray, R. 2015. Writing in social spaces: A social processes approach to academic writing. London: Routledge.

Paliadelis, P., V. Parker, G. Parmenter, and M. Maple. 2015. “'Right' for publication: Strategies for supporting novice writers across health and medical disciplines." Australian Health Review 39(2): 165-168. 
Pololi, L., S. Knight, and K. Dunn. 2004. "Facilitating scholarly writing in academic medicine.” Journal of General Internal Medicine 19(1): 64-68.

Prochaska, J.O. 2013. “Transtheoretical model of behavior change.” In Encyclopedia of Behavioral Medicine (1997-2000). New York: Springer.

Stern, N. 2016. Building on success and learning from experience: An independent review of the research excellence framework. London: UK Government Department for Business, Energy and Industrial Strategy.

Thow, M.K., K. Graham, and C. Lee. 2013. The Healthy Heart Book. Champaign IL: Human Kinetics.

Tremblay, M.S., R.C. Colley, T.J. Saunders, G.N. Healy, and N. Owen. 2010. "Physiological and health implications of a sedentary lifestyle." Applied Physiology, Nutrition, and Metabolism 35(6):725-740.

Van Egeren, L. 2000. "Stress and coping and behavioral organization.” Psychosomatic Medicine 62(3): 451-460. 


\section{Appendix 1: The Writing Skills Quiz}

\section{(a)( (1)}

\section{Writing Skills Quiz}

Consider the following list of 10 key writing skills. Evaluate your ability in each area on a scale of 1 to 10 (with 1 meaning very poor ability and 10 meaning excellent ability).

1.2.3.4.5.6.

7. 8. 9. 10 .

I am able to synthesize lots of research and see the big picture.

I write accurate summaries of research in clear, easy-to-follow prose.

I critique research to see potential logical gaps or flaws in reasoning.

I identify significant connections among things that are not usually linked.

I write clear transition sentences between sections of my argument.

I use transition words (i.e., "however" or "in addition") to indicate the relationship between ideas.

I clearly articulate research questions or the problem statement. I vary sentence length, using short sentences as well as longer ones. I craft the introduction so the reader understands my topic and why it matters. I write in active voice rather than passive voice when it offers greater precision.

(C) 2015 Academic Coaching \& Writing LLC

Academic Coaching \& Writing LLC | academiccoachingandwriting.org | p 760.635 .1545 


\section{Appendix 2: The Writing Process Quiz}

\section{(a) (c) (w)}

\section{Writing Process Quiz}

Rate the following 10 items on a scale of 1 to 10 , with 1 meaning this item is never part of your writing process and 10 meaning it is almost always part of your process.

1.___ I stop researching and begin writing, even if I don't feel completely ready.

2.___ I work on my writing project for 1 to 2 hours a day, 4 or 5 days each week.

3. ___ I arrange my schedule to write at the time of day when I am at my sharpest.

4.___ I take frequent breaks when I write for a long period.

5.___ I don't beat myself up if I miss a day of scheduled writing.

6.___ I give myself small rewards when I stick to my planned writing schedule.

7.___ I spill out really rough drafts and don't try to perfect every paragraph before moving on.

8. ___ I freewrite to generate ideas, particularly when I feel stuck.

9.___ I understand that producing a good manuscript requires revising and working through multiple drafts.

10. _ I I am comfortable sharing drafts with and getting feedback from a trusted colleague, editor, or coach.

(C) 2015 Academic Coaching \& Writing LLC

Academic Coaching \& Writing LLC | academiccoachingandwriting.org | p 760.635 .1545 